\title{
Association of autophagy related gene polymor- phisms with neutrophilic airway inflammation in adult asthma
}

Duy Le Pham ${ }^{1,2}$, Seung-Hyun Kim², Purevsuren Losol ${ }^{2}$, Eun-Mi Yang ${ }^{2}$, Yoo Seob Shin ${ }^{2}$, Young-Min Ye ${ }^{2}$, and Hae-Sim Park ${ }^{1,2}$

Departments of ${ }^{1}$ Biomedical Sciences and ${ }^{2}$ Allergy and Clinical Immunology, Ajou University School of Medicine, Suwon, Korea; ${ }^{3}$ Department of Molecular Biology and Genetics, Health Sciences University of Mongolia, Ulaanbaatar, Mongolia

Received: December 26, 2014

Revised : June 2, 2015

Accepted: August 17, 2015

\section{Correspondence to}

Hae-Sim Park, M.D.

Department of Allergy and Clinical Immunology, Ajou University School of Medicine, 206 World cup-ro, Yeongtong-gu, Suwon 16499, Korea

Tel: +82-31-219-5196

Fax: +82-31-219-5154

E-mail: hspark@ajou.ac.kr
Background/Aims: Role of autophagy in neutrophil function and the association of autophagy and autophagy related (ATG) gene polymorphisms with asthma susceptibility were suggested. In this study, we investigated the genetic association of $A T G_{5}$ and $A T G 7$ polymorphisms with asthma risk, severity and neutrophilic airway inflammation.

Methods: We recruited 408 asthma patients and 201 healthy controls. Sputum neutrophil counts were determined by H\&E staining. Serum interleukin 8 (IL-8) levels were measured by enzyme-linked immunosorbent assay (ELISA). Genetic polymorphisms of ATG5 $(-769 \mathrm{~T}>\mathrm{C},-335 \mathrm{G}>\mathrm{A}$, and $8830 \mathrm{C}>\mathrm{T})$ and $A T G 7(-100 \mathrm{~A}>\mathrm{G}$ and $25108 \mathrm{G}>C$ ) were genotyped. The functional activities of $A T G_{5}-769 \mathrm{~T}>\mathrm{C}$ and $-335 \mathrm{G}>\mathrm{A}$ variants were investigated by luciferase reporter assays.

Results: No associations of ATG5 and ATG7 polymorphisms with asthma susceptibility and severity were found. ATG5 $-769 \mathrm{~T}>\mathrm{C}$ and $-335 \mathrm{G}>\mathrm{A}$ were in complete linkage disequilibrium. In the asthma group, GA/AA genotypes at ATG $5-335 \mathrm{G}>\mathrm{A}$ were associated with higher neutrophil counts in sputum $(p<0.05)$; CC/TT genotype at $A T G_{5} 8830 \mathrm{C}>\mathrm{T}$ associated with lower $\mathrm{FEV} 1 \%$ predicted value $(p<0.05)$. DNA fragments containing ATG5 $-769 \mathrm{~T}$ and $-335 \mathrm{G}$ alleles had higher promoter activities compared to those with $-769 \mathrm{C}$ and $-335 \mathrm{~A}$ in both human airway epithelial cells (A549, $p<0.01$ ) and human mast cell (HMC-1, $p<0.001)$. GG and CC genotype at $A T G 7-100 A>G$ and $25108 \mathrm{G}>C$ were significantly associated with high serum levels of IL-8 ( $p<0.05$ for both variants).

Conclusions: Genetic polymorphisms of $A T G_{5}$ and $A T G_{7}$ could contribute to neutrophilic airway inflammation in the pathogenesis of adult asthma.

Keywords: Asthma; Autophagy; Polymorphism, genetic; Neutrophils

\section{INTRODUCTION}

Asthma is a chronic airway inflammatory disease characterized by airflow obstruction and bronchial hyperresponsiveness [1,2]. Asthmatic airway inflammation has heterogenous clinical phenotypes which can depend on different cellular inflammatory pathogenic mechanisms [3]. Eosinophil is considered as a key effector cell in astht ma [4,5]; however, abundant published data reported strong associations of airway neutrophilic inflammation with severe asthma, corticosteroid treatment responses, asthma exacerbations and asthma phenotypes/ 
endotypes [6]. The roles of neutrophil in asthma pathoa genesis are not completely understood and the genetic predictive factor for neutrophilic inflammatory phenotypes in asthma has not been identified.

Macroautophagy (referred as autophagy in this report) is a cellular process important to cell survival, by which damaged organelles and proteins are sequestered to autophagosomes and delivered to lysosomes for degradation [7]. Among the proteins that take part in autophagy pathway, autophagy related (ATG) 5 protein in the conjugation with ATG12, and ATG7 acting as E1-like enzyme play important roles in the maturation of autophagosomes by facilitating the elongation of isolation membranes (phagophore). Recently, autophagy has been implicated in inflammation and immune responses of airway diseases such as asthma and chronic obstructive pulmonary disease [8]. Autophagy plays crucial roles in innate as well as adaptive immune responses by supporting the proliferation, activation and function of various immune cells such as macrophages, neutrophils, mast cells, T and B cells [9-11]. Regarding neutrophils, autophagy was found to regulate cell differentiation, formation of neutrophil extracellular trap (NET) and cell death [12], which could contribute to the pathogenesis of immune diseases such as asthma. In asthma patients autophagosomes were detected more frequently in epithelial cells compared to those in healthy subjects [13]. In addition, single nucleotide polymorphisms (SNPs) of ATG5 such as rs510432 and rs12212740 were found to associate with asthma susceptibility and lung function $[13,14]$. These findings suggest an association of autophagy and ATG genetic polymorphisms in asthma pathogenesis.

Based on the findings, we investigated the association of ATG5 and ATG7 genetic polymorphisms with asthma susceptibility, severity and clinical features with a focus on neutrophilic inflammation in the present study.

\section{METHODS}

\section{Study subjects recruitment}

We enrolled 408 asthmatic patients and 201 healthy normal controls (NCs) from Ajou University Hospital (Suwon, Korea) to a case-controlled study. Asthma was diagnosed at the first evaluation based on a history of respiratory symptoms as well as the results of airway reversibility and hyperresponsiveness to methacholine following the Global Initiative for Asthma guideline. Severe asthma was defined as asthma that requires treatment with high dose inhaled corticosteroids plus a second controller and/or systemic corticosteroids to control it or that remains "uncontrolled" despite this therapy, follows American Thoracic Society guidelines [15]. All asthma patients were recruited when the disease was stable on their regular medications without any viral or bacterial airway infection. NCs were healthy individuals who had no history of asthma symptoms. All the subjects were provided written informed consents prior to participating in this study.

Atopy was defined as one or more positive reactions on a skin prick test with 55 common inhalant allergens (Bencard Co., Brentford, UK) with histamine and saline controls. Methacholine bronchial challenge tests were performed as previously described using doubled doses of methacholine (0.075 to $25 \mathrm{mg} / \mathrm{mL}$ ) [16]. The methacholine $\mathrm{PC} 2 \mathrm{O}$ value (the concentration of methacholine needed to produce a $20 \%$ decrease in forced expiratory volume in 1 second [FEV1]) was determined by interpolation from a dose-response curve.

\section{Sputum induction and blood collection}

Sputum induction was performed as previously described [17]. Briefly, asthma subjects were pretreated with $200 \mu \mathrm{g}$ salbutamol through a metered dose inhaler. The subjects then were inhaled nebulized sterile 3\% saline solution for 20 minutes through an ultrasonic nebulizer (Omron Co., Kyoto, Japan). Expectorated sputum was collected into a petri dish after excluding the saliva. Simultaneously with sputum collection, venous blood was collected into acid citric dextrose containing tubes (BD Falcon, Franklin Lakes, NJ, USA) for genomic DNA preparation and Vacuette tubes (Greiner Bio-One, Monroe, NC, USA) for serum collection.

\section{Assessment of sputum neutrophil count}

Each sputum sample in petri dish was weighted and transferred into a $50 \mathrm{~mL}$ polystyrene tube. Four times volume $(\mathrm{v} / \mathrm{w})$ of freshly prepared dithiothreitol $0.1 \%$ (DTT, Sigma, St. Louis, MO, USA) diluted in distilled water was added to each sputum tube followed by incubation at $37^{\circ} \mathrm{C}$ for 20 minutes with occasionally gentle vortex to dissociate the disulfide bonds of the mucus. 
Table 1. The single nucleotide polymorphisms of ATG 5 and $A T G_{7}$ in this study

\begin{tabular}{|c|c|c|c|c|c|c|}
\hline \multirow{2}{*}{$\begin{array}{l}\text { Gene } \\
\text { ATG5 }\end{array}$} & \multicolumn{2}{|c|}{ SNP } & \multirow{2}{*}{$\begin{array}{c}\text { Chromosome } \\
6\end{array}$} & \multirow{2}{*}{$\begin{array}{l}\text { Location } \\
\text { Promoter }\end{array}$} & \multirow{2}{*}{$\begin{array}{l}\text { MAF } \\
0.419\end{array}$} & \multirow{2}{*}{$\begin{array}{c}\text { HWE } \\
\text { (p value) }\end{array}$} \\
\hline & $-769 \mathrm{~T}>\mathrm{C}$ & rs506027 & & & & \\
\hline & $-335 \mathrm{G}>\mathrm{A}$ & rs510432 & 6 & Promoter & 0.419 & 0.961 \\
\hline & $8830 \mathrm{C}>\mathrm{T}$ & rs573775 & 6 & Intron 1 & 0.331 & 0.530 \\
\hline \multirow[t]{2}{*}{ ATG7 } & $-100 A>G$ & rs2594971 & 3 & Promoter & 0.32 & 0.530 \\
\hline & $25108 \mathrm{G}>\mathrm{C}$ & rs1375206 & 3 & Intron 1 & 0.342 & 0.012 \\
\hline
\end{tabular}

p values were obtained by chi-square tests in normal control group.

SNP, single nucleotide polymorphism; MAF, minor allele frequency; HWE, Hardy-Weinberg equilibrium.

Table 2. The amplifying and extension primers and probes for $A T G_{5}$ and $A T G_{7}$ polymorphisms genotyping

\begin{tabular}{lll}
\hline Gene & Locus $(\mathrm{SNP}$ ID $)$ & \multicolumn{1}{c}{ Primer } \\
\hline ATG5 & $-769 \mathrm{~T}>\mathrm{C}(\mathrm{rs} 506027)$ & Forward: AGTCCAACTCCAAGAAGATTT \\
& & $\begin{array}{l}\text { Reverse: GTCCCAGCTACTGGAGAGT } \\
\text { Genotyping: TTATTAGTAAGTTTACCAATTATTA }\end{array}$ \\
& $-335 \mathrm{G}>\mathrm{A}(\mathrm{rs} 510432)$ & TaqMan assay, predesigned \\
& $8830 \mathrm{C}>\mathrm{T}(\mathrm{rs} 573775)$ & TaqMan assay, predesigned \\
ATG7 & $-100 \mathrm{~A}>\mathrm{G}(\mathrm{rs} 2594971)$ & TaqMan assay, predesigned \\
& $25108 \mathrm{G}>\mathrm{C}(\mathrm{rs} 1375206)$ & TaqMan assay, predesigned \\
\hline
\end{tabular}

SNP, single nucleotide polymorphism.

The reaction was stopped by added phosphate buffer saline (PBS) in a volume equal to the sputum plus DTT solution. The tubes were centrifuged at 1,500 rpm for 5 minutes. The cell pellet was resuspended in $50 \mathrm{~mL}$ PBS and filtered through a $40 \mu \mathrm{m}$ nylon filter (Millipore, Bedford, MS, USA). Total cell count and cell viability were determined by staining with Trypan Blue (Sigma) and observing under an inverted microscope. To assess differential cell count, a cytospin slide of each sample was prepared, fixed with methanol and performed hematoxylin and eosin stain. All slides were overread (total 500 cells) and the samples with more than $80 \%$ squamous cells were excluded from analysis. Sputum neutrophil count was expressed as percentage of neutrophils among non-squamous cells in each sample.

\section{SNP selection and genotyping}

Genomic DNA was prepared from peripheral blood samples using Puregene Blood Core Kit (Qiagen, Germantown, MD, USA) following the manufacturer's protocol. We screened for SNPs located on promoter and 5'-untraslated region (UTR) of ATG5 and ATG7 from 40 healthy Korean volunteers by direct sequencing. Three SNPs of ATG 5 including $-769 \mathrm{~T}>\mathrm{C},-335 \mathrm{G}>\mathrm{A}$ in promoter region and $8830 \mathrm{C}>\mathrm{T}$ in 5 'UTR, were selected. Two SNPs of $A T G 7$, including $-100 \mathrm{~A}>\mathrm{G}$ in promoter and $25108 \mathrm{G}>\mathrm{C}$ in 5 'UTR, were selected. ATG5 and ATG7 are located on chromosome 6 and 3, respectively. The information of ATG5 and ATG7 polymorphisms are shown in Table 1. Minor allele frequency of all selected SNPs was over than $5 \%$. Target SNPs were genotypes from all genomic DNA samples of study subjects using a primer extension method and the SNaPshot ddNTP primer extension kit (Applied Biosystems, Foster City, CA, USA) with primers shown in Table 2.

Preparation of ATG5 constructs for promoter assays A 3201 base-pair DNA fragment that contains ATG5 $-769 \mathrm{~T}>\mathrm{C}$ and $-335 \mathrm{G}>\mathrm{A}$ was amplified using the following primers: forward primer 5'CTCTATCGATAGGTACCAAGTGATGGTTAGGGTTCATGG-3' and reverse primer 5'-GATCGCAGATCTCGAGGCCCTCCGTGTTCTGCCTAA-3'. The 3' end of each primer (underlined) contains homologous sequences with ATG5 
and the 5' ends contain 15-16 bases homologous to each end of the linear pGL3-basic vector (Promega, Madison, WI, USA). Linear vector was prepared using Kpnı and Xho1 restriction enzymes (Takara, Shuzo, Japan). The PCR amplified fragments were gel-purified using Expin Gel kit (GeneAll, Seoul, Korea) and then cloned into the linear pGL3-basic vectors using In-fusion HD cloning kit (Clontech Laboratories Inc., Mountain View, CA, USA) following the manufacturer's manual.

\section{Cell culture}

Human airway epithelial cell (A549) and human mast cell (HMC-1) were purchased from American Type Culture Collection (Manassas, VA, USA). A549 cells were cultured in RPMI-1640 and HMC-1 cells were cultured in Iscove's modified Dulbecco's medium (Gibco, Grand Island, NY, USA) supplemented with 10\% heat-inactivated fetal bovine serum (FBS), $100 \mathrm{U} / \mathrm{mL}$ penicillin $\mathrm{G}$ sodium and $100 \mu \mathrm{g} / \mathrm{mL}$ of streptomycin sulfate (Gibco). The cells were maintained at $370 \mathrm{C}$ in $5 \% \mathrm{CO}_{2}$ humidified atmosphere.

\section{Endogenous mRNA expressions of ATG5 and ATG7}

Total mRNA was extracted from various cell lines using Easy-Blue reagent (Intron Biotechnology, Seongnam, Korea) according to the manufacturer's protocol. cDNA was synthesized by reverse transcription (RT)-PCR from $3 \mu \mathrm{g}$ of total mRNA using MMLV-RTase (Promega) under optimized reaction condition (reaction buffer: 50 $\mathrm{mM}$ Tris-HCl pH 8.3, $17 \mathrm{mM} \mathrm{KCl,} 3 \mathrm{mM} \mathrm{MgCl}_{2}, 10 \mathrm{mM}$ DTT, 2 mM dNTP, 0.5 U/mL RNase inhibitors [Promega] at $42^{\circ} \mathrm{C}$ for 1 hour 10 minutes and extanded at $70^{\circ} \mathrm{C}$ for 10 minutes). The mRNA expression levels of ATG5 and ATG7 was evaluated by PCR using the specific primers (ATG5: forward 5'-TCTCTTGACTGCAGTACCTT'TTC-3' and reverse 5'-CGTGTCTGATACTGTAAGCCTT'T-3'; ATG7: forward 5'-CGACGCTCAGTAGCCTGTAG-3' and reverse 5'-TTTCTATCCCCTCCCCCTGG-3'), which was normalized by beta-actin mRNA expression level using specific primers (forward 5'-TCCTTCTGCATCCTGTCGGC-3' and reverse 5'-CAAGAGATGGCCACGGCTGC-3').

\section{Transient transfection and dual luciferase assay}

A549 cells were transfected with constructed plasmid DNA using lipofectamine (Invitrogen, Carlsbad, CA, USA) following the manufacturer's protocol. Briefly, $1 \times$
$10^{5}$ cells/well were seeded onto 12-well plate to obtain $70 \%$ to $80 \%$ confluence. Cells were transfected with $1 \mu \mathrm{g}$ of constructed plasmid DNA, 5 ng of Renilla plasmid DNA, $5 \mu \mathrm{L}$ lipofectamine and grown for 48 hours. HMC-1 cells were transfected with plasmid constructs using a microporator (MP-100, Digital Bio Technology, Seoul, Korea) and Neon transfection system (Invitrogen). Each well of 12-well plate was filled with $1 \mathrm{~mL}$ of appropriate medium supplemented with $10 \%$ FBS. For each well, $5 \times 10^{5}$ cells mixed with constructed plasmid DNA $(1 \mu \mathrm{g})$ and Renilla plasmid DNA (5 ng) were suspended in $10 \mu \mathrm{L}$ of solution $\mathrm{R}$. The mixture then was shocked at $1,650 \mathrm{~V} / 20 \mathrm{~mA} /$ plus width 1 in the microporator pipette station containing $3 \mathrm{~mL}$ of solution E. Cells were then transferred into 12 -well plate and incubated for 24 hours at $37^{\circ} \mathrm{C}$ in $5 \% \mathrm{CO}_{2}$ humidified atmosphere. Transfected cells were lysed with passive lysis buffer (Promega). $10 \mu \mathrm{L}$ of each lysate was applied to a dual-luciferase reporter assay (Promega) using a Clarity Luminescence microplate reader (BioTek, Winooski, VT, USA) following the manufacturer's protocol. The pGL3-control (Promega) and promoter-less pGL3-basic vectors were used as positive and negative control, respectively. Transfection and luciferase assays were replicated in three independent experiments.

\section{Measurement of serum interleukin 8 by ELISA}

Levels of serum interleukin 8 (IL-8) in were measured by using an enzyme-linked immunosorbent assay (ELISA) kit (Endogen, Woburn, MA, USA) according to the manufacturer's protocol.

\section{Statistical analysis}

The chi-square test with one degree of freedom was used to test the frequency of each SNP for significant departure from the Hardy-Weinberg equilibrium in NC group; and $p$ values of less than 0.01 were considered statistically significant [18]. The haplotype block pattern was constructed using Haploview version 4.2 (http:// haploview.software.informer.com/4.2/). Haplotypes that had frequency of more than $5 \%$ were selected for statistical analysis.

Clinical characteristics were compared between the two study groups using Student $t$ test and chi-square test. Differences in genotype and haplotype frequencies between the study groups were examined by a lo- 
Table 3. Clinical characteristics of study subjects

\begin{tabular}{|c|c|c|c|}
\hline Characteristic & Asthma $(\mathrm{n}=408)$ & $\mathrm{NC}(\mathrm{n}=201)$ & $p$ value \\
\hline Age, yr & $42.4 \pm 13.3$ & $28.6 \pm 12.3$ & $<0.001^{\mathrm{a}}$ \\
\hline Male sex & $164 / 399(41.1)$ & $91 / 180(50.6)$ & $0.018^{b}$ \\
\hline Smoking & $60 / 136(44.1)$ & $6 / 48(12.5)$ & $0.003^{b}$ \\
\hline Atopy & $215 / 353(60.9)$ & $24 / 104(23.1)$ & $<0.001^{b}$ \\
\hline Severe asthma & $64 / 369(17 \cdot 3)$ & NA & NA \\
\hline FEV1\% predicted & $84.2 \pm 21.9$ & NA & NA \\
\hline Metacholine PC2O, mg/mL & $8.1 \pm 16.3$ & NA & NA \\
\hline Sputum neutrophil count, \% & $53.6 \pm 34.8$ & NA & NA \\
\hline Total IgE, IU/L & $402.8 \pm 710.9$ & NA & NA \\
\hline
\end{tabular}

Values are presented as mean \pm SD or number (\%).

$\mathrm{NC}$, normal control; $\mathrm{FEV} 1$, forced expiratory volume in 1 second; NA, not available.

${ }^{a} p$ values were obtained using one way analysis of variance (ANOVA).

${ }^{\mathrm{b}} \mathrm{p}$ values were obtained using chi-square test.

gistic regression analysis with codominant, dominant and recessive models after accounting for age and sex as covariates. Generalized linear models were applied to compare sputum neutrophil count and serum IL-8 level according to genotypes and haplotypes distribution in the asthma group. The statistical analyses used IBM SPSS version 20 (IBM Co., Armonk, NY, USA) and $p$ values of less than 0.05 were considered statistically significant.

\section{RESULTS}

\section{Clinical characteristics of study subjects}

Table 3 demonstrates the clinical characteristics of study subjects. Asthma patients were older than NCs (42.4 \pm 13.3 vs. $28.6 \pm 12.3, p<0.001$ ). Smoking and atopy rate were significantly higher in the asthma group compared to those of NC group ( $p=0.003$ and $p<0.001$, respectively). Among asthma patients, $17.3 \%$ were classified as severe asthma. Mean sputum neutrophil count of the asthma group was $53.6 \% \pm 34.8 \%$.

\section{Allele, genotype and haplotype frequency of ATG5 and ATG7 polymorphisms}

The distributions of the three SNPs of ATG5 and two SNPs of ATG7 did not depart significantly from the Hardy-Weinberg equilibrium in NC group $(p>0.01$ for all SNPs) (Table 1). All the SNPs of each ATG5 and ATG7

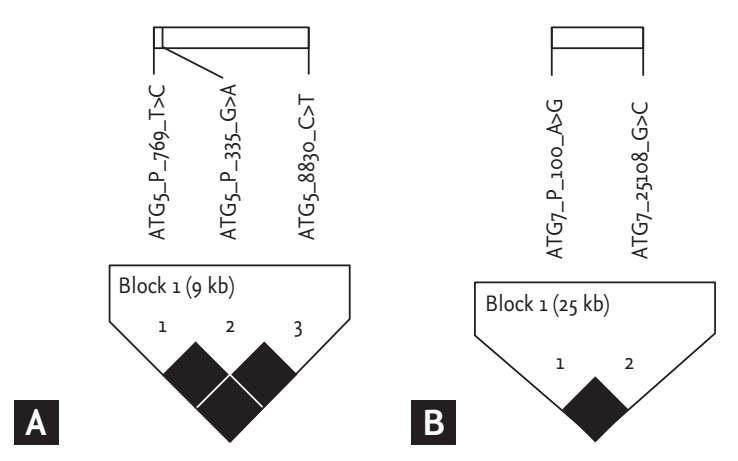

Figure 1. Linkage disequilibrium plot of $A T_{5}$ (A) and $A T G_{7}$ (B) genetic polymorphisms using Haploview with confidence bounds color scheme. All single nucleotide polymorphisms were in strong linkage disequilibrium.

were in strong linkage disequilibrium (Fig. 1). Interestingly, the two promoter SNPs of ATG5 gene $(-769 \mathrm{~T}>\mathrm{C}$ and $-335 \mathrm{G}>\mathrm{A}$ ) were in a complete linkage disequilibrium in our study population; consequently, the statistically analyzed data of $-335 \mathrm{G}>\mathrm{A}$ were shown as the representatives for the two ATG5 promoter SNPs. Three common haplotypes ( $\mathrm{HT}_{1}[\mathrm{AC}], \mathrm{HT}_{2}$ [GT], $\mathrm{HT}_{3}$ [GC]) for ATG5 $-335 \mathrm{G}>\mathrm{A}$ and $8830 \mathrm{C}>\mathrm{T}$; and two common haplotypes (HT1 [AG], HT2 [GC]) for the two SNPs of ATG7 were constructed using Haploview software. The haplotypes that have a frequency more than $5 \%$ were selected for analysis. The distribution of genotypes and haplotypes of $A T G_{5}$ and $A T G 7$ polymorphisms in the two study groups was not significantly different (Tables 4 and 5); and no significant differences in those distributions were 
Table 4. Distribution of genotypes and haplotypes of $A$ TG $_{5}$ genetic polymorphisms into the two study groups

\begin{tabular}{|c|c|c|c|c|}
\hline $\mathrm{SNP} / \mathrm{HT}$ & Genotype & Asthma $(n=408)$ & Normal control $(\mathrm{n}=201)$ & $p$ value \\
\hline \multirow[t]{3}{*}{$-335 \mathrm{G}>\mathrm{A}$} & GG & $133 / 404(32.9)$ & $66 / 200(33.0)$ & 0.238 \\
\hline & GA & $175 / 404(43 \cdot 3)$ & $100 / 100(50.0)$ & 0.275 \\
\hline & $\mathrm{AA}$ & $96 / 404(23.8)$ & $34 / 200(17.0)$ & 0.386 \\
\hline \multirow[t]{3}{*}{$8830 \mathrm{C}>\mathrm{T}$} & $\mathrm{CC}$ & $177 / 406(43.6)$ & $93 / 201(46.3)$ & 0.442 \\
\hline & $\mathrm{CT}$ & $182 / 406(44.8)$ & $84 / 201(41.8)$ & 0.097 \\
\hline & $\mathrm{TT}$ & $47 / 406(11.6)$ & $24 / 201$ (11.9) & 0.998 \\
\hline \multirow[t]{3}{*}{$\mathrm{HT} 1[\mathrm{AC}]$} & $\mathrm{HT} 1 / \mathrm{HT}_{1}$ & $96 / 396(24.2)$ & $34 / 198(17.2)$ & 0.197 \\
\hline & $\mathrm{HT} 1 /-$ & $172 / 396(43.4)$ & $98 / 198(49.5)$ & 0.339 \\
\hline & $-1-$ & $128 / 396(32.3)$ & $66 / 198(33 \cdot 3)$ & 0.237 \\
\hline \multirow[t]{3}{*}{$\mathrm{HT}_{2}[\mathrm{GT}]$} & $\mathrm{HT}_{2} / \mathrm{HT}_{2}$ & $46 / 396(11.6)$ & $24 / 198(12.1)$ & 0.337 \\
\hline & HT2/- & $175 / 396(44.2)$ & $83 / 198$ (41.9) & 0.776 \\
\hline & $-1-$ & $175 / 396(44.2)$ & $91 / 198$ (46.0) & 0.108 \\
\hline \multirow[t]{3}{*}{$\mathrm{HT}_{3}[\mathrm{GC}]$} & $\mathrm{HT}_{3} / \mathrm{HT}_{3}$ & $15 / 396(3.8)$ & $16 / 198(8.1)$ & 0.631 \\
\hline & $\mathrm{HT}_{3} /-$ & $131 / 396(33.1)$ & $67 / 198(33.8)$ & 0.918 \\
\hline & $-1-$ & $250 / 396(63.1)$ & $115 / 198(58.1)$ & 0.314 \\
\hline
\end{tabular}

Values are presented as number (\%). Each $p$ value was calculated using the codominant, dominant and recessive models. Logistic regression analysis was applied to control age and sex as covariates.

SNP, single nucleotide polymorphism; HT, haplotype.

Table 5. Distribution of genotypes and haplotypes of ATG7 genetic polymorphisms into the two study groups

\begin{tabular}{|c|c|c|c|c|}
\hline SNP/HT & Genotype & Asthma $(\mathrm{n}=408)$ & Normal control $(\mathrm{n}=201)$ & $p$ value \\
\hline \multirow[t]{3}{*}{$-100 A>G$} & $\mathrm{AA}$ & $185 / 402(46.0)$ & $86 / 201(42.8)$ & 0.427 \\
\hline & AG & $189 / 402(47.0)$ & $100 / 201(49.8)$ & 0.999 \\
\hline & GG & $28 / 402(7.0)$ & $15 / 201(7.5)$ & 0.313 \\
\hline \multirow[t]{3}{*}{$25108 \mathrm{G}>C$} & GG & $168 / 403(41.7)$ & $78 / 200(39.0)$ & 0.467 \\
\hline & GC & $202 / 403(50.1)$ & $107 / 200(53.5)$ & 0.785 \\
\hline & $\mathrm{CC}$ & $33 / 403(8.2)$ & $15 / 200(7.5)$ & 0.274 \\
\hline \multirow[t]{3}{*}{$\mathrm{HT}_{1}[\mathrm{AG}]$} & $\mathrm{HT}$ l/ HTl & $166 / 399(41.6)$ & $78 / 200(39.0)$ & 0.503 \\
\hline & HTl/- & $200 / 399(50.1)$ & $107 / 200(53.5)$ & 0.747 \\
\hline & $-1-$ & $33 / 399(8.3)$ & $15 / 200(7.5)$ & 0.294 \\
\hline \multirow[t]{3}{*}{$\mathrm{HT}_{2}$ [GC] } & $\mathrm{HT}_{2} / \mathrm{HT}_{2}$ & $28 / 399(7.0)$ & $14 / 200(7.0)$ & 0.490 \\
\hline & $\mathrm{HT} 2 /-$ & $188 / 399(47.1)$ & $100 / 200(50.0)$ & 0.327 \\
\hline & $-1-$ & $183 / 399(45 \cdot 9)$ & $86 / 200(43.0)$ & 0.845 \\
\hline
\end{tabular}

Values are presented as number (\%). Each $p$ value was calculated using the codominant, dominant and recessive models. Logistic regression analysis was applied to control age and sex as covariates.

SNP, single nucleotide polymorphism; HT, haplotype.

noted according to severity of asthma (Tables 6 and 7).

\section{Clinical characteristics according to ATG5 and ATG7 polymorphisms}

Fig. 2A shows the comparison of clinical characteristics according to the distributions of ATG5 genotypes in the asthma group. Asthmatics that carried GA/AA genotype at $A T G 5-335 \mathrm{G}>\mathrm{A}$ had significantly higher sputum neutrophil counts compared to those carrying GG genotypes $(59.5 \% \pm 33.5 \%$ vs. $39.8 \% \pm 34.9 \%, p=0.025)$. Asth- 
Table 6. Distribution of genotypes and haplotypes of ATG5 genetic polymorphisms in asthma group according to asthma severity

\begin{tabular}{|c|c|c|c|c|}
\hline $\mathrm{SNP} / \mathrm{HT}$ & Genotype & Severe asthma $(n=64)$ & Non-severe asthma $(n=305)$ & $p$ value \\
\hline \multirow[t]{3}{*}{$-335 \mathrm{G}>\mathrm{A}$} & GG & $21 / 64(32.8)$ & $99 / 301(32.9)$ & 0.773 \\
\hline & GA & $26 / 64(40.6)$ & $130 / 301(43.2)$ & 0.609 \\
\hline & $\mathrm{AA}$ & $17 / 64(26.6)$ & $72 / 301(23.9)$ & 0.994 \\
\hline \multirow{3}{*}{$8830 \mathrm{C}>\mathrm{T}$} & $\mathrm{CC}$ & $29 / 64(45 \cdot 3)$ & $133 / 303(43.9)$ & 0.659 \\
\hline & $\mathrm{CT}$ & $24 / 64(37.5)$ & $138 / 303(45 \cdot 5)$ & 0.178 \\
\hline & $\mathrm{TT}$ & $11 / 64(17.2)$ & $32 / 303(10.6)$ & 0.767 \\
\hline \multirow[t]{3}{*}{$\mathrm{HT} 1 \mathrm{AC}]$} & $\mathrm{HT} 1 / \mathrm{HT}_{1}$ & $17 / 62(27.4)$ & $72 / 295(24.4)$ & 0.622 \\
\hline & $\mathrm{HT} 1 /-$ & $26 / 62(41.9)$ & $127 / 295(43.1)$ & 0.800 \\
\hline & $-1-$ & $19 / 62(30.6)$ & $96 / 295(32.5)$ & 0.560 \\
\hline \multirow[t]{3}{*}{$\mathrm{HT} 2$ [GT] } & $\mathrm{HT}_{2} / \mathrm{HT}_{2}$ & $11 / 62(17.7)$ & $31 / 295(10.5)$ & 0.687 \\
\hline & HT2/- & $22 / 62(35 \cdot 5)$ & $133 / 295(45.1)$ & 0.656 \\
\hline & $-1-$ & $29 / 62(46.8)$ & $131 / 295(44.4)$ & 0.136 \\
\hline \multirow[t]{3}{*}{$\mathrm{HT}_{3}[\mathrm{GC}]$} & $\mathrm{HT}_{3} / \mathrm{HT}_{3}$ & $2 / 62(3.2)$ & $10 / 295(3.4)$ & 0.241 \\
\hline & $\mathrm{HT}_{3} /-$ & $16 / 62(25.8)$ & $104 / 295(35 \cdot 3)$ & 0.163 \\
\hline & $-1-$ & $44 / 62(71.0)$ & $181 / 295(61.4)$ & 0.867 \\
\hline
\end{tabular}

Values are presented as number (\%). Each p value was calculated using the codominant, dominant and recessive models. Logistic regression analysis was applied to control age and sex as covariates.

SNP, single nucleotide polymorphism; HT, haplotype.

Table 7. Distribution of genotypes and haplotypes of ATG7 genetic polymorphisms in asthma group according to asthma severity

\begin{tabular}{|c|c|c|c|c|}
\hline $\mathrm{SNP} / \mathrm{HT}$ & Genotype & Severe asthma $(n=64)$ & Non-severe asthma $(n=305)$ & $p$ value \\
\hline \multirow[t]{3}{*}{$-100 A>G$} & $\mathrm{AA}$ & $27 / 64(42.2)$ & $138 / 299(46.2)$ & 0.397 \\
\hline & AG & $30 / 64(46.9)$ & $141 / 299(47.2)$ & 0.175 \\
\hline & GG & $7 / 64(10.9)$ & $20 / 299(6.7)$ & 0.740 \\
\hline \multirow[t]{3}{*}{$25108 \mathrm{G}>\mathrm{C}$} & GG & $23 / 64(35 \cdot 9)$ & $126 / 300(42.0)$ & 0.151 \\
\hline & GC & $32 / 64(50.0)$ & $151 / 300(50.3)$ & 0.069 \\
\hline & $\mathrm{CC}$ & $9 / 64(14.1)$ & $23 / 300(7.7)$ & 0.439 \\
\hline \multirow[t]{3}{*}{$\mathrm{HT} 1[\mathrm{AG}]$} & $\mathrm{HT} 1 / \mathrm{HT} 1$ & $23 / 64(35 \cdot 9)$ & $124 / 296(41.9)$ & 0.155 \\
\hline & $\mathrm{HT} 1 /-$ & $32 / 64(50.0)$ & $149 / 296(50.3)$ & 0.075 \\
\hline & $-1-$ & $9 / 64(14.1)$ & $23 / 296(7.8)$ & 0.441 \\
\hline \multirow[t]{3}{*}{$\mathrm{HT} 2[\mathrm{GC}]$} & $\mathrm{HT} 2 / \mathrm{HT}_{2}$ & $7 / 64(10.9)$ & $20 / 296(6.8)$ & 0.418 \\
\hline & HT2/- & $30 / 64(46.9)$ & $140 / 296(47 \cdot 3)$ & 0.769 \\
\hline & $-1-$ & $27 / 64(42.2)$ & $136 / 296(45 \cdot 9)$ & 0.182 \\
\hline
\end{tabular}

Values are presented as number (\%). Each $p$ value was calculated using the codominant, dominant and recessive models. Logistic regression analysis was applied to control age and sex as covariates.

SNP, single nucleotide polymorphism; HT, haplotype.

matics carrying CC/CT genotype at $A T G 58830 \mathrm{C}>\mathrm{T}$ had significantly lower $\mathrm{FEV}_{1} \%$ predicted values compared to the carriers of TT genotype $(83.3 \% \pm 22.1 \%$ vs. $92.3 \%$ $\pm 19.2 \%, p=0.021)$. Additionally, the prevalence of asth- matics with $\mathrm{FEV}_{1} \%$ predicted value $<80 \%$ tended to be higher in those carrying ATG5 $8830 \mathrm{CC} / \mathrm{CT}$ genotype than in those carrying TT genotype (41.0\% vs. $22.6 \%, p=$ 0.053). Fig. $2 \mathrm{~B}$ shows that asthmatics carrying ATG5 $\mathrm{HT}_{1}$ 

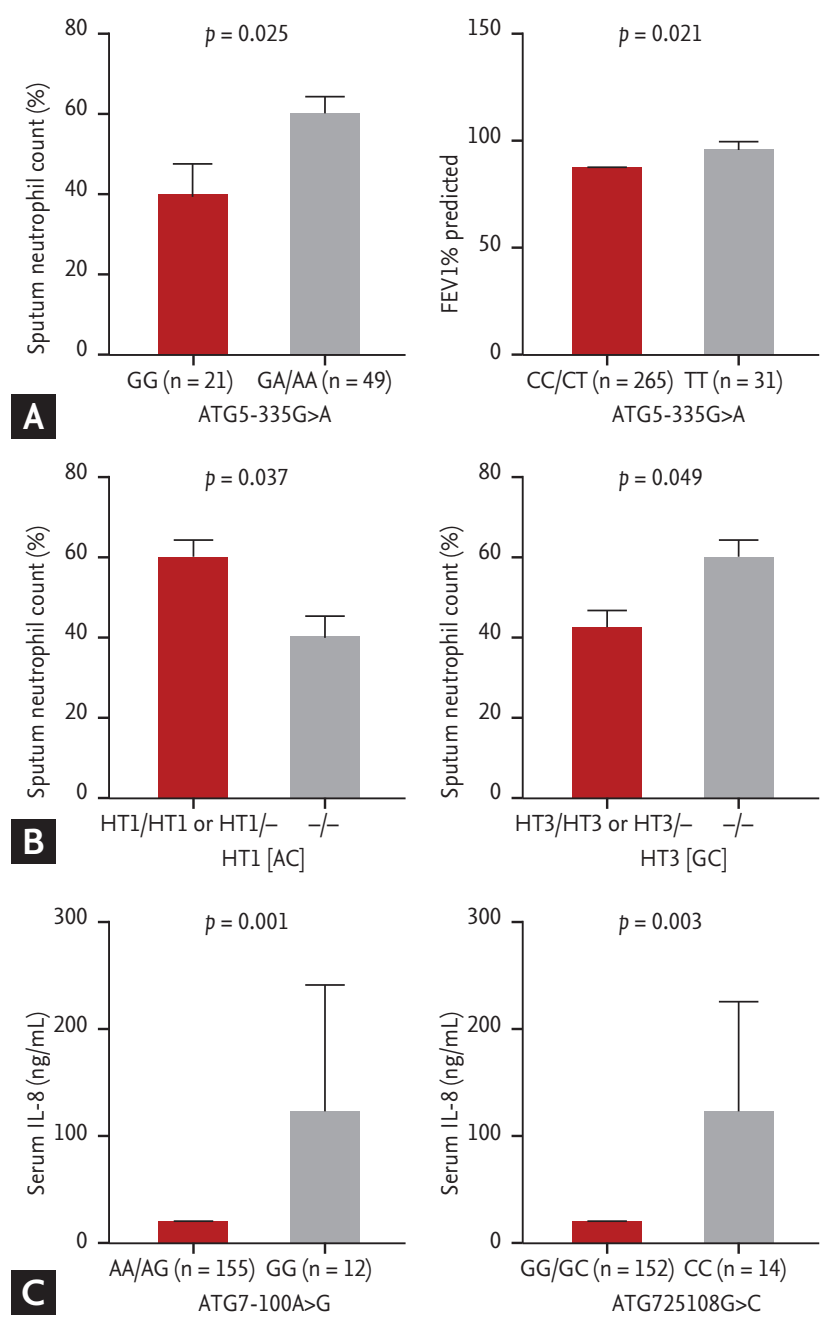

Figure 2. Comparison of clinical parameters according to the genotypes of $A T G_{5}$ and $A T G_{7}$ polymorphisms in asthmatic patients. (A) Clinical parameters according to the genotypes of ATG5 $-335 \mathrm{G}>\mathrm{A}$ and $8830 \mathrm{C}>\mathrm{T}$. (B) Clinical parameters according to the $\mathrm{HT}_{1}[\mathrm{AC}]$ and $\mathrm{HT}_{3}[\mathrm{GC}]$ of ATG5 polymorphisms. (C) Serum levels of interleukin (IL) 8 according to $A T G 7-100 A>G$ and $25108 \mathrm{G}>$ C. A $p$ value was obtained by generalized linear models adjusted for age and sex as covariates.

[AC] haplotype had a significantly higher sputum neutrophil count compared to non-carriers $(58.9 \% \pm 33.6 \%$ vs. $39.6 \% \pm 35.5 \%, p=0.037$ ); while asthmatic carriers of $\mathrm{HT}_{3}$ [GC] haplotype had a slightly but significantly lower sputum neutrophil count compared to non-carriers $(43.5 \% \pm 35.1 \%$ vs. $60.1 \% \pm 33.6 \%, p=0.049)$. No associations of HT2 [GT] with clinical parameters were noted.

Regarding ATG7 polymorphisms (Fig. 2C), serum IL-8 levels were significantly higher in asthmatic carriers of GG genotype at $-100 \mathrm{~A}>\mathrm{G}$ as well as those carrying CC

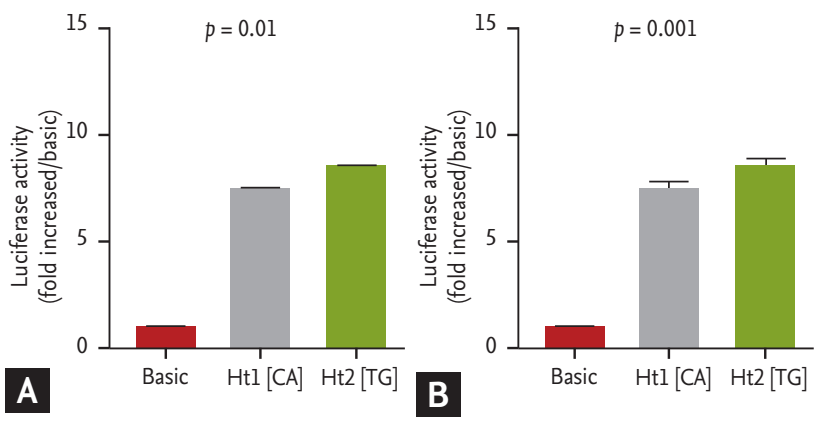

Figure 3. Functional promoter activities of ATG5 polymorphisms. DNA fragments containing Ht1 [CA] or Ht2 [TG] of ATG5 -769 T>C and $-335 \mathrm{G}>\mathrm{A}$ were cloned into pGL3-basic vectors. Plasmid constructs were transfected into A549 cells (A) and HMC-1 cells (B). Promoter activities of the DNA fragments were evaluated by dual-luciferase report assays. Transfections and luciferase assays were performed in three independent experiments (total $n=9$ ). Values are presented as mean $\pm \mathrm{SD}$; A p value was obtained by one way ANOVA.

genotype at $25108 \mathrm{G}>\mathrm{C}$ compared to the carriers of $\mathrm{AA} /$ AG and GG/GC genotypes $(137 \pm 445 \mathrm{pg} / \mathrm{mL}$ vs. $24.2 \pm 55.5$ $\mathrm{pg} / \mathrm{mL}, p=0.001 ; 123 \pm 418 \mathrm{pg} / \mathrm{mL}$ vs. $24.5 \pm 55.9 \mathrm{pg} / \mathrm{mL}, p$ $=0.003$; respectively).

\section{Transcriptional activity of ATG5 promoter polymor- phisms}

In order to select the target cell lines to investigate the functional promoter activity of ATG5 promoter polymorphisms, we evaluated the endogenous expression of ATG5 in various human cell lines including lung epithelial cell (A549), bronchial epithelial cell (Beas-2B), promyelocytic leukemia cell (HL-6o), leukemic monocyte lymphoma cell (U937) and mast cell (HMC-1). A549 and HMC-1 cell line, known to play role in asthma pathogenesis, were selected based on their high expressions of $A^{-1 G_{5}}$ (data not shown).

We constructed two DNA fragments that contained Ht1 [CA] with two minor alleles, and Ht2 [TG] with two major alleles of $A T G 5$ promoter SNPs as described in the Method section for dual luciferase assays. Plasmids with DNA fragments containing major haplotype exhibited significantly higher luciferase activity compared to those containing minor haplotype in both $\mathrm{A}_{549}(p<0.01)$ (Fig. 3A) and HMC-1 cells ( $p<0.001$ ) (Fig. 3B).

\section{DISCUSSION}

Previous reports demonstrated the associations of ATG5, 
but not ATG7, polymorphisms with asthma susceptibility and lung function $[13,14]$. In the present study with Korean adult asthmatics, we identified two promoter SNPs of $A T G_{5},-769 \mathrm{~T}>\mathrm{C}$ and $-335 \mathrm{G}>\mathrm{A}$, associated with sputum neutrophil count; and two SNPs of ATG7 gene, $-100 A>G$ and $25108 \mathrm{G}>A$, associated with serum level of IL-8.

In a previous genome wide association study with White/Caucasian children asthmatics, allele G of ATG5 $-335 \mathrm{G}>\mathrm{A}(\mathrm{rs510432})$ was found to be associated with increased asthma risk. In the present study, the association of ATG $-335 \mathrm{G}>\mathrm{A}$ with asthma susceptibility was not noted; however, GA/AA genotypes at ATG5 $-335 \mathrm{G}>\mathrm{A}$ was associated with a higher sputum neutrophil count in adult asthmatic patients. Intriguingly, the two ATG5 promoter SNPs were in a complete linkage equilibrium in our study population, which explains the same finding observed in regards to the sputum neutrophil count in association with $A T G_{5}-7699^{\circ}>\mathrm{C}$. These findings suggested a possibly functional effect of the two ATG5 promoter SNPs on transcriptional activity.

Martin et al. [14] demonstrated that ATG5 -335G allele increased a higher promoter activity compared to A allele; and two asthma-associated transcription factors, STAT1 and C-Fos, were assumed to bind to ATG5 $-335 \mathrm{G}>\mathrm{A}$. Consistently, we found that Htı [TG] of ATG5 $-769 \mathrm{~T}>\mathrm{C}$ and $-335 \mathrm{G}>\mathrm{A}$ enhanced significantly higher promoter activity compared to Ht2 [CA]. We do not have a direct evidence to explain for that the major haplotype of ATG5 promoter polymorphisms was associated with lower sputum neutrophil counts but enhanced the higher promoter activity. However, Yousefi et al. [19] identified a calpain-dependently cleaved fragment of mouse ATG5 protein related to spontaneous neutrophil apoptosis, which was independent to autophagy process. In addition, ATG5 could contribute to cell death by interaction with Fas-associated protein with death domain under the stimulation of interferon gamma (INF- $\gamma$ ) [20]. Because the formation of autophagosome in mouse only needs a small amount of ATG5 [21], the overexpression of $A T G_{5}$ in human, which is affected by ATG5 promoter polymorphisms, probably increases intracellular autophagy levels and/or elicits neutrophil apoptosis mediated by the ATG5 cleaved fragment.

Asthmatics carrying $\mathrm{C}$ allele of $A T G 58830 \mathrm{C}>\mathrm{T}$ had a lower $\mathrm{FEV}_{1} \%$ predicted value than carriers of the TT genotype. However, we did not observe a difference in the transcriptional activity of the two alleles of this SNP (data not shown). In the present study population, we observed that all subjects carrying ATG5 -335 A allele concomitantly carried ATG5 $8830 \mathrm{C}$ allele; however the reverse linkage was not found. This linkage explained for that $\mathrm{HT}_{1}[\mathrm{AC}]$ and $\mathrm{HT}_{3}[\mathrm{GC}]$ of $\mathrm{ATG}_{5}-335 \mathrm{G}>\mathrm{A}$ and $8830 \mathrm{C}>\mathrm{T}$ were associated only with sputum neutrophil count, but not FEVı\% predicted value. This finding suggests that the two SNPs of ATG5 could play role in asthma pathogenesis by different mechanisms, which needs to be revealed by further studies.

GG genotype at $A T G 7-100 A>G$ and CC genotype at $A T G 725108 \mathrm{G}>\mathrm{C}$ was also found to be associated with high serum levels of IL-8, a major chemoattractant and stimulator of neutrophils. However, these two variants did not exhibit different transcriptional activities in our transfection and luciferase assay system (data not shown).

The fact that the two promoter SNPs of ATG5 and the two SNPs of ATG7 were all associated with neutrophilic inflammatory markers suggested an interaction between the two genes. However, we did not find the associations of ATG5 and ATG7 polymorphisms in genegene interactions with asthma susceptibility as well as asthma clinical parameters in the present study (data not shown). This finding suggests independent roles of the two genes in neutrophilic inflammation of asthma.

Autophagy machinery was identified in murine as well as human neutrophils [22,23]. Reactive oxygen species (ROS) possibly trigger and regulate autophagy in neutrophils and other cell types [23,24]. Inflammatory cells including neutrophils that are recruited into the asthmatic airways produced greater ROS levels compared to those in normal subjects [25]. Concomitantly, greater number of double membrane autophagosomes were depicted in airway epithelial cells and fibroblast from asthmatics compared to those from healthy subjects [13]. These findings suggested a high level of autophagy occurring in cells that are involved in asthma pathogenesis, including neutrophils.

It is not fully understood if autophagy is a harmful or protective mechanism in asthma. However, autophagy has been known to protect the cells from damage or even cell death, as well as be essential for the survival, differentiation and function of various kinds of cell in- 
volved in inflammatory and immune responses [10,2628]. Consequently, autophagy is able to augment the effects of immune cells to prolong airway inflammation that increase asthma severity. In addition, respiratory viral infection, which could lead to asthma exacerbation, also could activate ATG genes and autophagy [29]. Concurrently, Remijsen et al. [12] demonstrated that autophagy is crucial for the formation of NET which was identified in airways of allergic asthma patients and could be triggered by IL-8 [30,31]. NET is a structure composited by DNA net with histones and coated by several proteins such as neutrophil elastase and myeloperoxidase released from activated neutrophils. The role of NET in asthma pathogenesis is under investigations; however, neutrophil enzymes that coat the NET may damage the airway epithelia [32]. IL-8 levels, sputum neutrophil counts and NETs are all increased in neutrophilic asthmatics, and likely contribute to asthma severity [32-35]. Additionally, both neutrophils and IL-8 are features of difficult-to-treat asthma [36]. These findings suggest a potent role of autophagy in neutrophil activation which may enhance the severity of asthma.

We had a limitation in investigating the gene-environment interaction in the present study, which could be strictly evaluated by a further prospective study. In addition, larger cohorts and further functional studies are needed to reveal the role of autophagy and ATG genes in the pathogenesis of asthma.

We provide evidence showing the association of ATG5 and $A T G 7$ gene polymorphisms with several markers of neutrophilic asthma phenotype, and the different functional effects of ATG5 promoter SNPs on transcriptional activities. The findings suggest a role of ATG genetic polymorphisms and autophagy machinery in neutrophil survival and function, which may contribute to the neutrophilic airway inflammation in asthma.

\section{KEY MESSAGE}

1. ATG5 and ATG7 genetic polymorphisms were associated with several makers for neutrophilic asthma phenotype such as sputum neutrophil counts and serum interleukin 8 levels.

2. ATG gene polymorphisms and autophagy machinery could contribute to neutrophilic airway inflammation in asthma pathogenesis.

\section{Conflict of interest}

No potential conflict of interest relevant to this article was reported.

\section{Acknowledgments}

This study was supported by a grant of the Korean Health 21 R\&D Project, Ministry of Health and Welfare, Republic of Korea (HI14C2628).

\section{REFERENCES}

1. Lotvall J, Akdis CA, Bacharier LB, et al. Asthma endotypes: a new approach to classification of disease entities within the asthma syndrome. J Allergy Clin Immunol 2011;127:355-360.

2. Holgate ST. Mechanisms of asthma and implications for its prevention and treatment: a personal journey. Allergy Asthma Immunol Res 2013;5:343-347.

3. Fahy JV. Eosinophilic and neutrophilic inflammation in asthma: insights from clinical studies. Proc Am Thorac Soc 2009;6:256-259.

4. Jo EJ, Kim MY, Lee SE, et al. Eosinophilic airway inflammation and airway hyperresponsiveness according to aeroallergen sensitization pattern in patients with lower airway symptoms. Allergy Asthma Immunol Res 2014;6:39-46.

5. Schleich FN, Manise M, Sele J, Henket M, Seidel L, Louis R. Distribution of sputum cellular phenotype in a large asthma cohort: predicting factors for eosinophilic vs neutrophilic inflammation. BMC Pulm Med 2013;13:11.

6. Douwes J, Gibson P, Pekkanen J, Pearce N. Non-eosinophilic asthma: importance and possible mechanisms. Thorax 2002;57:643-648.

7. Deretic V, Saitoh T, Akira S. Autophagy in infection, inflammation and immunity. Nat Rev Immunol 2013;13:722737.

8. Ryter SW, Choi AM. Autophagy in the lung. Proc Am Thorac Soc 2010;7:13-21.

9. Bhattacharya A, Eissa NT. Autophagy and autoimmunity crosstalks. Front Immunol 2013;4:88.

10. Mihalache CC, Simon HU. Autophagy regulation in macrophages and neutrophils. Exp Cell Res 2012;318:11871192.

11. Ushio H, Ueno T, Kojima Y, et al. Crucial role for autophagy in degranulation of mast cells. J Allergy Clin Immu- 
nol 2011;127:1267-1276.e6.

12. Remijsen Q, Vanden Berghe T, Wirawan E, et al. Neutrophil extracellular trap cell death requires both autophagy and superoxide generation. Cell Res 2011;21:290-304.

13. Poon AH, Chouiali F, Tse SM, et al. Genetic and histologic evidence for autophagy in asthma pathogenesis. J Allergy Clin Immunol 2012;129:569-571.

14. Martin LJ, Gupta J, Jyothula SS, et al. Functional variant in the autophagy-related 5 gene promotor is associated with childhood asthma. PLoS One 2012;7:e33454.

15. Chung KF, Wenzel SE, Brozek JL, et al. International ERS/ ATS guidelines on definition, evaluation and treatment of severe asthma. Eur Respir J 2014;43:343-373.

16. Park HS, Kim HY, Nahm DH, Son JW, Kim YY. Specific IgG, but not specific IgE, antibodies to toluene diisocyanate-human serum albumin conjugate are associated with toluene diisocyanate bronchoprovocation test results. J Allergy Clin Immunol 1999;104(4 Pt 1):847-851.

17. Nahm DH, Park HS. Analysis of induced sputum for studying allergen-specific IgE antibodies in airway secretion from asthmatic patients. Clin Exp Allergy 1998;28:686-693.

18. Lunetta KL. Genetic association studies. Circulation 2008;118:96-101.

19. Yousefi S, Perozzo R, Schmid I, et al. Calpain-mediated cleavage of Atg5 switches autophagy to apoptosis. Nat Cell Biol 2006;8:1124-1132.

20. Pyo JO, Jang MH, Kwon YK, et al. Essential roles of Atg5 and FADD in autophagic cell death: dissection of autophagic cell death into vacuole formation and cell death. J Biol Chem 2005;280:20722-20729.

21. Hosokawa N, Hara Y, Mizushima N. Generation of cell lines with tetracycline-regulated autophagy and a role for autophagy in controlling cell size. FEBS Lett 2006;580:2623-2629.

22. Huang J, Canadien V, Lam GY, et al. Activation of antibacterial autophagy by NADPH oxidases. Proc Natl Acad Sci U S A 2009;106:6226-6231.

23. Mitroulis I, Kourtzelis I, Kambas K, et al. Regulation of the autophagic machinery in human neutrophils. Eur J
Immunol 2010;40:1461-1472.

24. Scherz-Shouval R, Elazar Z. Regulation of autophagy by ROS: physiology and pathology. Trends Biochem Sci 2011;36:30-38.

25. Dworski R. Oxidant stress in asthma. Thorax 2000;55 Suppl 2:S51-S53.

26. He MX, McLeod IX, Jia W, He YW. Macroautophagy in T lymphocyte development and function. Front Immunol 2012;3:22.

27. Pua HH, Dzhagalov I, Chuck M, Mizushima N, He YW. A critical role for the autophagy gene Atg 5 in T cell survival and proliferation. J Exp Med 2007;204:25-31.

28. Conway KL, Kuballa P, Khor B, et al. ATG5 regulates plasma cell differentiation. Autophagy 2013;9:528-537.

29. Jyothula SS, Eissa NT. Autophagy and role in asthma. Curr Opin Pulm Med 2013;19:30-35.

30. Dworski R, Simon HU, Hoskins A, Yousefi S. Eosinophil and neutrophil extracellular DNA traps in human allergic asthmatic airways. J Allergy Clin Immunol 2011;127:12601266.

31. Brinkmann V, Reichard U, Goosmann C, et al. Neutrophil extracellular traps kill bacteria. Science 2004;303:1532-1535.

32. Cheng OZ, Palaniyar N. NET balancing: a problem in inflammatory lung diseases. Front Immunol 2013;4:1.

33. Jatakanon A, Uasuf C, Maziak W, Lim S, Chung KF, Barnes PJ. Neutrophilic inflammation in severe persistent asthma. Am J Respir Crit Care Med 1999;160(5 Pt 1):1532-1539.

34. Kikuchi S, Nagata M, Kikuchi I, Hagiwara K, Kanazawa M. Association between neutrophilic and eosinophilic inflammation in patients with severe persistent asthma. Int Arch Allergy Immunol 2005;137 Suppl 1:7-11.

35. Silvestri M, Bontempelli M, Giacomelli M, et al. High serum levels of tumour necrosis factor-alpha and interleukin-8 in severe asthma: markers of systemic inflammation? Clin Exp Allergy 2006;36:1373-1381.

36. Chun YH, Park JY, Lee H, et al. Rhinovirus-infected epithelial cells produce more IL-8 and RANTES compared with other respiratory viruses. Allergy Asthma Immunol Res 2013;5:216-223. 